\title{
Relação entre adubação fosfatada e deficiência hídrica em soja
}

\author{
Relationship between phosphorus supplying and water deficit in soybean
}

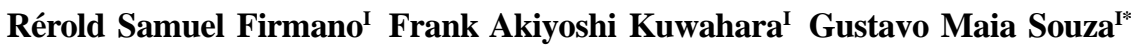

RESUMO

Este estudo teve como objetivo verificar os efeitos do fósforo sobre a fotossíntese e o crescimento de Glycine max (L.) Merr. da cultivar 'Embrapa 48' sob deficiência hídrica controlada, em condições de casa de vegetação, considerando a hipótese de que suplementações de fósforo poderiam aumentar a tolerância das plantas ao déficit hídrico. Após a formação do primeiro par de folhas totalmente expandidas, foi iniciado o processo de indução de deficiência hídrica, utilizando dois regimes de irrigação, com $100 \%$ e $25 \%$ de reposição da evapotranspiração. A deficiência hídrica causou reduções significativas no acúmulo de massa seca, no potencial de água foliar, na condutância estomática e na assimilação líquida de $\mathrm{CO}_{2}$ em todos os tratamentos. Os resultados das trocas gasosas indicaram que a suplementação de $P$, na adubação de G. $\max$ da cultivar 'Embrapa 48', resultou em uma redução parcial dos efeitos da deficiência hídrica como suposto inicialmente. Porém, apenas em relação à biomassa do sistema radicular detectou-se algum efeito mitigador do $P$ nas plantas sob deficiência hídrica.

Palavras-chave: crescimento, deficiência hídrica, fósforo, fotossíntese, Glycine Max.

\section{ABSTRACT}

The objective of this study was to investigate the effects of phosphorus supplying on growth and photosynthesis of Glycine max (L.) Merr. cv. 'Embrapa 48', cultivated under water deficit in greenhouse conditions, taking into account the hypothesis that phosphorus suply could improve plant tolerance to drough. After the development of the first pair of totally expanded leaves, it was initiate the process of induction of water deficit, using two irrigation levels, $100 \%$ and $25 \%$ of evapotranspiration replacement Water deficit reduced dry mass, leaf water potential, stomatal conduction, and net $\mathrm{CO}_{2}$ assimilation regardless $P$ supply. The results of the photosynthetic analysis indicated that phosphorus supply was just partially effective to reduce water deficit effects on $\mathbf{G}$ max cv. 'Embrapa 48'. However, additional $P$ supply influenced positively the production of plants root biomass under water deficit.

Key words: Glycine max, growth, phosphorus, photosynthesis, water deficit.

\section{INTRODUÇÃO}

A soja é uma das culturas de maior importância econômica no Brasil, sendo cultivada em todo o território nacional. Todavia, a ocorrência de adversidades climáticas ainda é um fator de risco e de insucesso no cultivo de soja, conforme mostra o relatório sobre a seguridade agrícola elaborado pelo Ministério do Planejamento. Dentre essas adversidades, a ocorrência de secas tem sido apontada como o principal evento prejudicial à cultura $(71 \%$ dos casos) (GOPEFERT et al., 1993; EMBRAPA, 2004).

A soja é particularmente sensível à deficiência hídrica durante a emergência das plântulas e na fase de florescimento e enchimento dos grãos, podendo ocorrer perdas significativas de produção, dependendo da duração e intensidade da falta de água (DOSS \& THURLOW, 1974; CÂMARA \& HEIFFIG, 2000). No entanto, segundo KRON et al. (2008), plantas de soja submetidas à deficiência hídrica durante a fase de desenvolvimento V4 podem ter sua tolerância aumentada em razão da falta de água em estágios posteriores.

'Laboratório de Ecofisiologia Vegetal (ECOLAB), Universidade do Oeste Paulista (UNOESTE), 19067-175, Presidente Prudente, SP, Brasil. E-mail: gustavo@unoeste.br.*Autor para correspondência. 
A deficiência hídrica provoca uma redução na taxa de assimilação líquida de $\mathrm{CO}_{2}$ (A) (SHARKEY \& SEEMANN, 1989). O efeito em A pode ser parcialmente explicado por uma baixa concentração intercelular de $\mathrm{CO}_{2}$ (Ci) devido ao fechamento estomático (CHAVES et al., 2002). Todavia, a limitação da assimilação de $\mathrm{CO}_{2}$ sob deficiência hídrica pode ser parcialmente devida à inibição da síntese de ribulose bifosfato, associada a um baixo conteúdo de ATP, provavelmente devido à perda da atividade da ATP sintase (TEZARA et al., 1999).

Vários estudos investigaram a disponibilidade de fósforo em relação ao metabolismo fotossintético, mas poucos avaliaram os efeitos de déficit de água nessa relação (SANTOS et al., 2004). Um decréscimo da reciclagem de fósforo entre citoplasma e estroma (FOYER, 1988), gerado por uma redução da absorção de $\mathrm{P}$ em função de um déficit hídrico no solo (NOVAIS \& SMYTH, 1999; SANTOS et al., 2006), pode levar a um decréscimo no consumo ou na produção de ATP e NADPH, uma menor regeneração de ribulose-1,5-bifosfato, um substrato da fotossíntese (AZCÓN-BIETO, 1983), um decréscimo na expressão de genes relacionados à fotossíntese (PAUL \& PELLNY, 2003), um fechamento estomático (GOLDSCHMIDT \& HUBER, 1992; NAKANO et al., 2000), e a um aumento da resistência à difusão de $\mathrm{CO}_{2}$ nas células do mesofilo foliar (NAFZIGER \& KOLLER, 1976; NAKANO et al., 2000).

Considerando a alta sensibilidade da soja à deficiência hídrica no período reprodutivo, este estudo teve como objetivo testar a hipótese de que suplementações de fósforo poderiam aumentar a tolerância das plantas ao déficit hídrico nas fases de pleno florescimento (R2) e no período de enchimento de grãos (R5), tendo em vista que tal suplementação poderia favorecer o processo fotossintético por meio da otimização do transporte de trioses-P do cloroplasto para o citosol, bem como favorecer a síntese de ATP e enzimas do metabolismo fotossintético.

\section{MATERIAL E MÉTODOS}

O experimento foi conduzido na casa de vegetação do Campus II da Universidade do Oeste Paulista, no Município de Presidente Prudente, oeste do Estado de São Paulo. O material avaliado foi a cultivar 'Embrapa 48' (Glycine max (L.) Merr.), que é proveniente do cruzamento entre Davis x Paraná x IAS $4 \times$ BR 5. Tem crescimento determinado e maturação superprecoce, com ciclo médio de 115 dias, além de possuir resistência e tolerância a diversas doenças (EMBRAPA SOJA, 2007).
$\mathrm{O}$ experimento foi realizado em arranjo inteiramente casualizado, num esquema fatorial $4 \times 2$ (quatro doses de fósforo e dois regimes de irrigação) e quatro repetições. As doses de $\mathrm{P}$ suplementar avaliadas foram equivalentes a $0,50,100,200 \mathrm{~kg} \mathrm{ha}^{-1}$, incorporadas ao solo 30 dias após a emergência das plântulas na forma de Superfosfato triplo.. Duas vezes por semana os vasos eram rearranjados aleatoriamente para diminuir o efeito de fatores ambientais não considerados neste estudo. Foram utilizados vasos contendo $12 \mathrm{~kg}$ de solo argissolo vermelho-amarelo distrófico, possuindo as seguintes características químicas: $\mathrm{pH} \mathrm{em} \mathrm{CaCl}_{2}$ de 4,8, acidez potencial $(\mathrm{H}+\mathrm{Al})$ de $21 \mathrm{mmol} \mathrm{dm}^{-3}$, alumínio $\left(\mathrm{Al}^{3+}\right) 1 \mathrm{mmol}_{\mathrm{c}} \mathrm{dm}^{-3}$, matéria orgânica (M.O.) $7 \mathrm{~g} \mathrm{dm}^{-3}$, cálcio $\left(\mathrm{Ca}^{2+}\right) 9 \mathrm{mmol}_{\mathrm{c}} \mathrm{dm}^{-3}$, magnésio $\left(\mathrm{Mg}^{2+}\right) 8 \mathrm{mmol}_{\mathrm{c}} \mathrm{dm}^{-3}$, potássio $\left(\mathrm{K}^{+}\right) 1,6 \mathrm{mmol}_{\mathrm{c}} \mathrm{dm}^{-3}$, fósforo $24 \mathrm{mg} \mathrm{dm}^{-3}$, enxofre $\left(\mathrm{SO}_{4}^{-2}\right) 1,3 \mathrm{mg} \mathrm{dm}^{-3}$, soma de bases (SB) $19 \mathrm{mmol}_{\mathrm{c}} \mathrm{dm}^{-3}$, CTC $39 \mathrm{mmol} \mathrm{dm}^{-3}$. Para o tipo de solo utilizado, essa concentração de $\mathrm{P}$ é considerada média.

Após o estabelecimento das plântulas, mantidas até então sob irrigação com $100 \%$ de reposição da água evapotranspirada, foi realizado um desbaste deixando apenas uma planta por vaso. Após a formação do primeiro par de folhas totalmente expandidas, foi iniciado o processo de indução de deficiência hídrica a partir da evaporação de um minitanque Classe A. As plantas em cada tratamento foram separadas em grupos, recebendo $100 \%$ ou $25 \%$ de reposição da água evapotranspirada diariamente. As lâminas para a irrigação foram calculadas com base em frações de evaporação do Tanque Classe A (ECA), utilizando a seguinte equação:

$$
h i=\frac{E C A \cdot k p \cdot k c \cdot \text { área do vaso }}{e f .}
$$

sendo: hi - lâmina de irrigação (L); ECA - evaporação do Tanque Classe A (mm); kp -coeficiente do Tanque Classe A $(0,80)$; kc - coeficiente da cultura; área do vaso $\left(706,8 \mathrm{~cm}^{2}\right)$ e ef a eficiência da aplicação $(\mathrm{ef}=1)$. $\mathrm{O}$ valor de $\mathrm{kp}$ foi estabelecido segundo MEDEIROS et al. (1997), os quais determinaram haver uma alta correlação entre a evaporação de um tanque classe A padrão e um minitanque classe $\mathrm{A}$, e nesse último a evaporação é, em média, $15 \%$ maior. Os valores de kc variaram ao longo do desenvolvimento da cultura, sendo utilizados os valores de 0,3 no início do desenvolvimento, de 0,7 a partir da fase V4, de 1,0 a partir da fase R1, e de 0,4 na fase final de desenvolvimento (DOORENBOS \& KASSAN, 1979).

As plantas foram avaliadas considerando as variáveis de trocas gasosas na folha e no potencial de água foliar em duas fases do período reprodutivo da cultura: período de pleno florescimento (R2) e no período de enchimento de grãos (R5). Ao final do cultivo, foi avaliada a produção de biomassa seca da 
parte aérea e da raiz, e calculado o índice de colheita (relação entre massa seca das vagens e a massa seca total da planta). A massa seca das plantas foi avaliada após secagem em estufa a $60^{\circ} \mathrm{C}$ até obtenção de massa constante.

As medidas de trocas gasosas (assimilação líquida de $\mathrm{CO}_{2}(\mathrm{~A})$, condutância estomática (gs), transpiração (E) e concentração intercelular de $\mathrm{CO}_{2}(\mathrm{Ci})$ foram realizadas com um medidor portátil de trocas gasosas por infravermelho (modelo CIRAS-2, PPSystem, UK). A eficiência instantânea do uso da água foi calculada como $\mathrm{A} / \mathrm{E}\left(\mu \mathrm{mol} \mathrm{CO} \mathrm{mmol}^{-1} \mathrm{H}_{2} \mathrm{O}\right)$. As medidas, em folhas visualmente sadias e totalmente expandidas, foram realizadas em condições ambientais de luz saturante $\left(1200 \mu \mathrm{mol}\right.$ fótons $\left.\mathrm{m}^{-2} \mathrm{~s}^{-1}\right)$, fornecida com uma fonte de luz com lâmpadas de tungstênioalogênio acoplada ao medidor de trocas gasosas, e $\mathrm{CO}$ atmosférico entre as 10 e $12 \mathrm{~h}$. O potencial de água foliar foi avaliado com uma câmara de pressão (modelo 1000, PMS Instruments, USA) em quatro folhas totalmente expandidas por tratamento, na manhã que antecedeu as medidas de trocas gasosas.

Os dados foram submetidos à análise de variância (ANOVA, $\mathrm{P}=0,05$ ), e as médias foram comparadas posteriormente pelo teste de Tukey $(\mathrm{P}=0,05)$, utilizando-se o programa Sisvar (versão 4.6, Universidade Federal de Lavras).

\section{RESULTADOS E DISCUSSÃO}

Observou-se que as plantas sob deficiência hídrica apresentaram um $\Psi$ menor $(\mathrm{P}<0,05)$, por volta de $-1,3 \mathrm{MPa}$, que as plantas com $100 \%$ de reposição hídrica ( $\Psi$ de aproximadamente - $0,6 \mathrm{MPa}$ ), não havendo diferença significativa $(\mathrm{P}>0,05)$ entre os tratamentos com $P$, tanto nas plantas irrigadas, quanto nas plantas sob deficiência hídrica. $\mathrm{Na}$ fase de enchimento de grãos (R5), os valores de $\Psi$ se mantiveram semelhantes aos valores da fase de plena floração (R2), sempre com as plantas sob deficiência hídrica, apresentando um $\Psi$ menor $(\mathrm{P}<0,05)$ com relação às plantas com $100 \%$ de reposição hídrica (Figura 1).

As plantas irrigadas no estágio R2 apresentaram, de maneira geral, valores de gs maiores $(\mathrm{P}<0,05)$ que as plantas com deficiência hídrica (Figura 1). Entre as plantas irrigadas, o tratamento que recebeu $200 \mathrm{~kg} \mathrm{ha}^{-1} \mathrm{de} \mathrm{P}$ apresentou maiores valores $(\mathrm{P}<0,05) \mathrm{de}$ gs que os demais tratamentos irrigados (Figura 1). As plantas irrigadas no estágio R5 apresentaram, de maneira geral, valores maiores $(\mathrm{P}<0,05)$ que as plantas deficientes (Figura 1). Entre as plantas irrigadas, os tratamentos-testemunha $\left(0 \mathrm{~kg} \mathrm{ha}^{-1} \mathrm{de} \mathrm{P}\right), 100$ e $200 \mathrm{~kg}$ $\mathrm{ha}^{-1}$ de $\mathrm{P}$ apresentaram valores maiores de gs $(\mathrm{P}<0,05)$ que as plantas do tratamento $50 \mathrm{~kg} \mathrm{ha}^{-1} \mathrm{de} \mathrm{P}$, porém não apresentaram diferença significativa $(\mathrm{P}<0,05)$ entre si (Figura 1).

Com relação às plantas deficientes no estágio R5, observou-se que os tratamentos 50 e $200 \mathrm{~kg}$ $\mathrm{ha}^{-1}$ de $\mathrm{P}$ apresentaram valores maiores $(\mathrm{P}<0,05)$ com relação aos tratamentos-testemunha $\left(0 \mathrm{~kg} \mathrm{ha}^{-1} \mathrm{de} \mathrm{P}\right) \mathrm{e}$ $100 \mathrm{~kg} \mathrm{ha}^{-1} \mathrm{de} \mathrm{P}$, que, por sua vez, não apresentaram diferença significativa $(\mathrm{P}>0,05)$ entre si. Embora os resultados tivessem apresentado alterações de gs aparentemente associadas às diferentes concentrações de $\mathrm{P}$, parece não haver nenhum tipo de explicação mecanística para isso, uma vez que o $\mathrm{P}$ não estaria ligado diretamente ao processo de controle da abertura estomática. A regulação da abertura estomática possui basicamente dois componentes, um ligado à pressão de turgor das células guarda, portanto um controle hidráulico, e outro ligado à concentração de $\mathrm{CO}_{2}$ intercelular $(\mathrm{Ci})$, neste último caso, uma redução na quantidade de $\mathrm{Ci}$ estimularia a abertura estomática e vise-versa (LAMBERS et al., 1998). Todavia, os resultados de $\mathrm{Ci}$ (dados não apresentados) não sustentam isso. Por outro lado, a suplementação de fósforo pode estar relacionada com uma acumulação de prolina, que é um ajustador osmótico (AL-KARAKI et al., 1996), o que poderia influenciar a regulação osmótica das células-guarda estomáticas.

A deficiência hídrica reduziu significativamente a fotossíntese líquida (A) em todas as condições avaliadas (Figura 2). Todavia, na fase R5, as reduções nos valores de $\mathrm{A}$ foram significativamente maiores nas plantas que não receberam suplementação de P. Além da abertura estomática como causa da redução da fotossíntese por limitação da entrada de $\mathrm{CO}_{2}$, essa redução em plantas submetidas à deficiência hídrica pode estar relacionada à limitação da síntese de ribulose-1,5-bifosfato (LAWLOR \& CORNIC, 2002). A limitação da síntese de RuBP provavelmente está ligada à redução na síntese de ATP (LAWLOR, 2002). A diminuição na síntese de ATP no cloroplasto, reduzindo as taxas fotossintéticas, poderia ser causada por uma baixa disponibilidade de fosfato inorgânico citoplasmático livre (Pi) trocado por triose-fosfato do cloroplasto por translocadores de fosfato que usam o Pi como um substrato (FLÜGGE et al., 2003). Assim, a suplementação com $\mathrm{P}$ em nosso experimento pode ter contribuído para minimizar os efeitos da deficiência hídrica como sugerido anteriormente, especialmente na fase R5, embora não tenha sido suficiente para manter a fotossíntese em níveis similares aos das plantas irrigadas.

A transpiração (E) das plantas irrigadas apresentou-se significativamente superior $(\mathrm{P}<0,05)$ com relação à transpiração das plantas sob deficiência hídrica (Figura 2). De maneira geral, as variações 


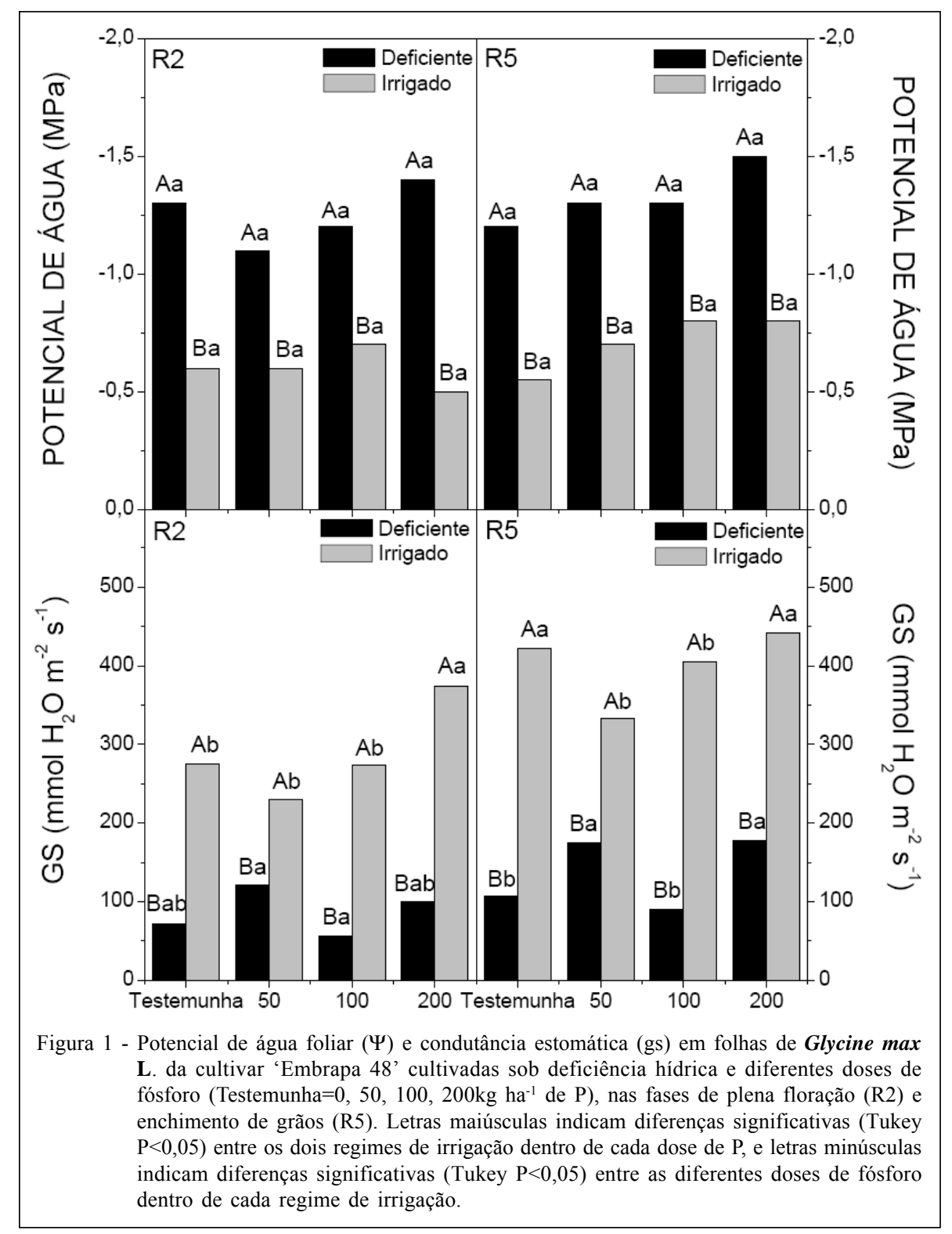

observadas na transpiração foram diretamente ligadas às variações da abertura estomática (Figuras 1 e 2). Plantas sob deficiência hídrica moderada frequentemente apresentam um aumento na eficiência do uso da água, uma vez que uma redução apenas parcial da abertura estomática limita mais fortemente a transpiração do que a entrada de $\mathrm{CO}$ (CHAVES et al., 2002; KRON et al., 2008). No entanto, como pode ser observado pelos resultados obtidos (Figura 2), de forma geral, os valores da EUA das plantas sob deficiência hídrica diminuíram, indicando que as plantas estariam sob uma restrição hídrica mais severa. Isso ocorre em função de um maior aumento da resistência em relação à difusão do $\mathrm{CO}_{2}$ no mesofilo, diminuindo a eficiência de carboxilação (LÂWLOR \& CORNIC, 2002).
Quanto à produção de biomassa, os resultados mostraram que a deficiência hídrica reduziu significativamente a biomassa na parte aérea, no sistema radicular e nas vagens. De forma geral, um aumento da suplementação de $\mathrm{P}$, sobretudo com a aplicação do equivalente a $200 \mathrm{~kg} \mathrm{ha}^{-1}$ de $\mathrm{P}$, tendeu a aumentar a biomassa nas plantas que receberam reposição de $100 \%$ da água evapotranspirada. Entretanto, entre as plantas cultivadas sob deficiência hídrica, não houve diferença significativa entre a produção de biomassa das partes analisadas em resposta às doses de $\mathrm{P}$, exceto em relação à biomassa da raiz onde as plantas que foram suplementadas com $\mathrm{P}$ apresentaram valores significativamente maiores em relação às plantas sem adição de $\mathrm{P}$. Todavia, isso não 


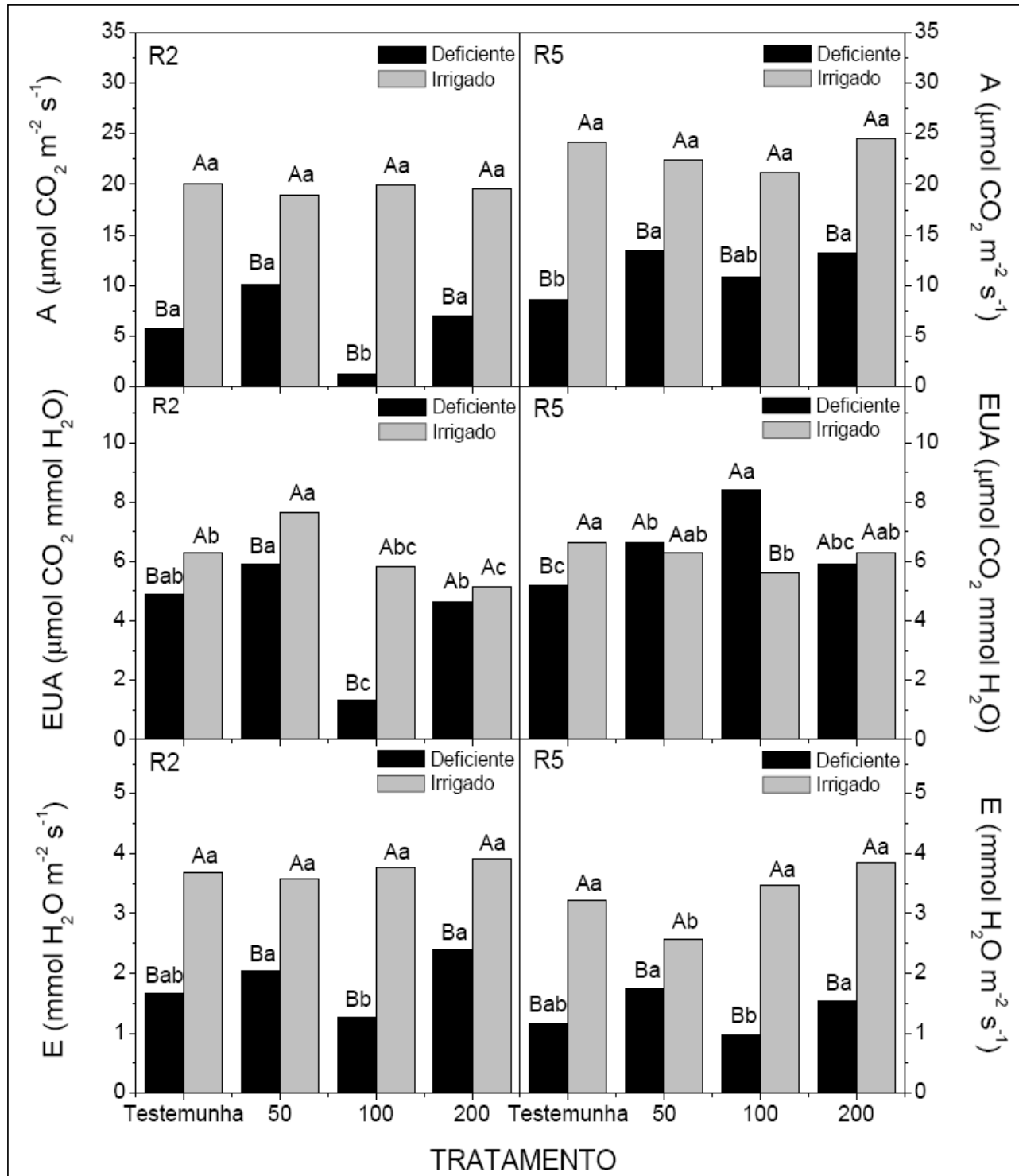

Figura 2 - Assimilação líquida de $\mathrm{CO}_{2}$ (A), transpiração (E) e eficiência do uso da água (EUA) em folhas de Glycine $\max$ L. da cultivar 'Embrapa 48' cultivadas sob deficiência hídrica e diferentes doses de fósforo (Testemunha $=0,50,100,200 \mathrm{~kg} \mathrm{ha}^{-1} \mathrm{de} P$ ), nas fases de plena floração (R2) e enchimento de grãos (R5). Letras maiúsculas indicam diferenças significativas (Tukey $\mathrm{P}<0,05$ ) entre os dois regimes de irrigação dentro de cada dose de $\mathrm{P}$, e letras minúsculas indicam diferenças significativas (Tukey $\mathrm{P}<0,05$ ) entre as diferentes doses de fósforo dentro de cada regime de irrigação.

impediu uma redução de biomassa em relação às plantas bem irrigadas (Figura 3). A partir do cálculo do índice de colheita (Figura 3), isto é, a relação entre a biomassa total da planta e biomassa das vagens colhidas, observou-se que não houve diferença significativa $(\mathrm{P}>0,05)$ entre nenhuma condição testada, sugerindo que os efeitos da deficiência hídrica foram similares entre os índices de produção avaliados e que o $\mathrm{P}$ não teve um efeito significativo sobre os índices de colheita dos tratamentos testados.
Como pode ser observado pelos resultados de produção de biomassa, o efeito do $\mathrm{P}$ foi significativo apenas entre as plantas que não tiveram restrição hídrica. $\mathrm{O}$ impacto de aplicações de fósforo sobre o aumento no desenvolvimento de plantas é reconhecido em diferentes culturas (HOFFMANN et al., 1995; GUSS et al., 1990; FONSECA et al., 1988). O fósforo é um componente estrutural de macromoléculas, como ácidos nucléicos e fosfolipídios, e também do adenosina trifosfato (ATP), sendo um elemento-chave de várias 


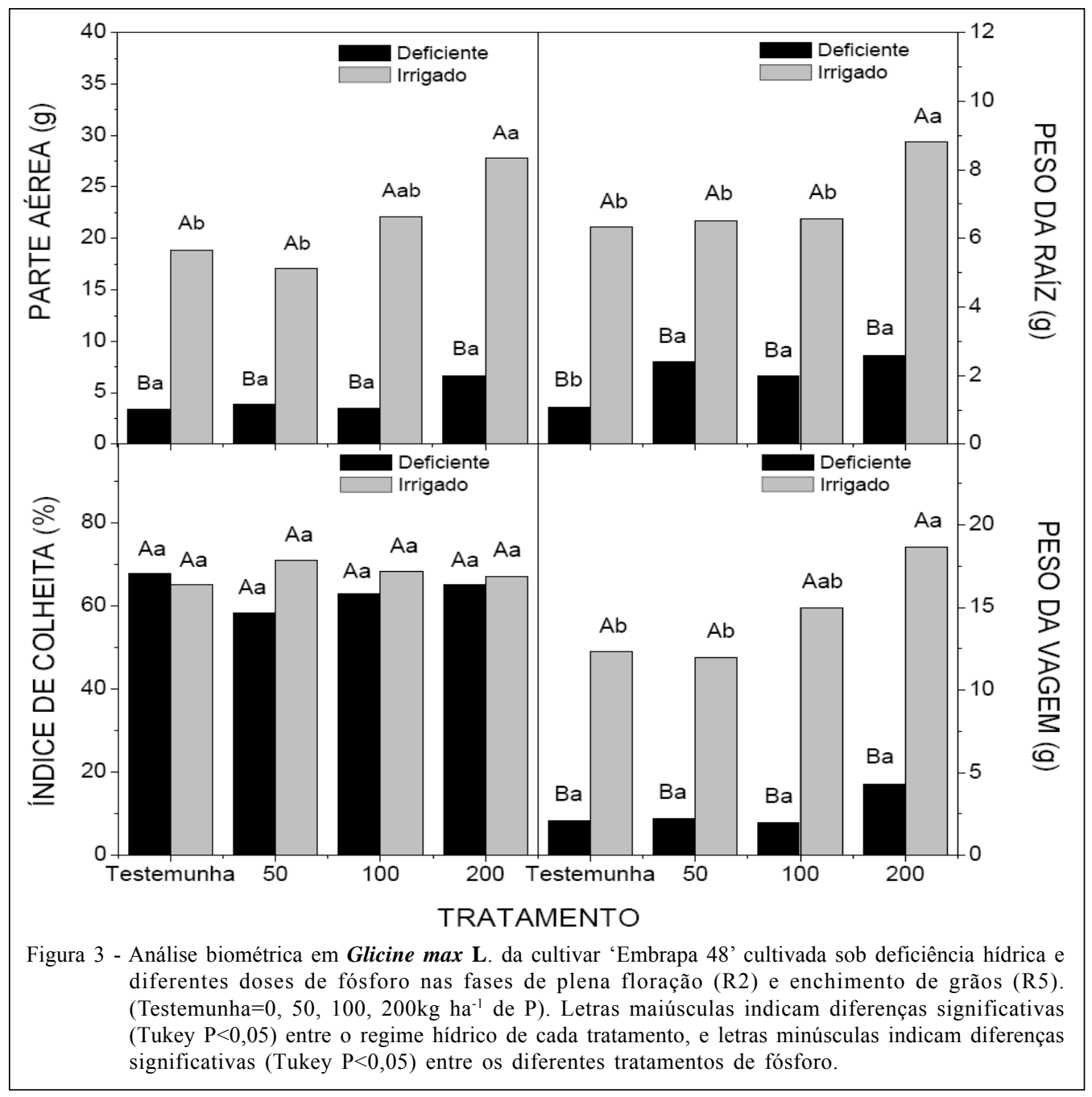

vias metabólicas e reações bioquímicas, tais como inúmeras etapas das vias fotossintéticas $\mathrm{C} 3$ e C4 e da glicólise (HOLFORD, 1997). Por outro lado, esse efeito não foi observado nas plantas sob deficiência hídrica provavelmente em função de uma limitação da absorção de fósforo promovida pela falta de água, visto que a absorção de Pi é dependente da disponibilidade de água no solo (NOVAIS \& SMYTH, 1999).

\section{CONCLUSÃO}

A hipótese de que o fósforo poderia atuar com um agente mitigador dos efeitos da deficiência hídrica sobre o crescimento e a fotossíntese de soja da cultivar 'Embrapa 48' foi parcialmente corroborada. A suplementação de $\mathrm{P}$ contribuiu para mitigar os efeitos da deficiência hídrica em relação à assimilação líquida de $\mathrm{CO}_{2}$, comparado-se com plantas que não receberam
$\mathrm{P}$ adicional. Todavia, tais efeitos não foram suficientes para conferir maior estabilidade à produção de biomassa nas vagens. Por outro lado, houve uma tendência de uma maior estabilidade na biomassa do sistema radicular, nas plantas suplementadas com $\mathrm{P}$.

\section{AGRADECIMENTOS}

Este estudo foi apoiado pela Fundação de Amparo à Pesquisa do Estado de São Paulo(FAPESP). GMS é bolsista produtividade do Conselho Nacional de Desenvolvimento Científico e Tecnológico (CNPq) e RSF recebeu bolsa de Iniciação Científica da FAPESP.

\section{REFERÊNCIAS}

AL-KARAKI G.N. et al. Phosphorus nutrition and water effects on proline accumulation in sorghum and bean. Journal of Plant Physiology, Leipzig, v.148, p.745-751, 1996. Disponível em: < http://cat.inist.fr/?aModele=afficheN\&cpsidt=3109138>. Acesso em: 17 abr. 2009. doi:10.1071/PP9880063. 
AZCÓN-BIETO, J. Inhibition of photosynthesis by carbohydrates in wheat leaves. Plant Physiology, Rockville, v.73, p.681$686,1983$.

CÂMARA, G.M.S.; HEIFFIG, L.S. Fisiologia, ambiente e rendimento da cultura da soja. In: CÂMARA, G.M. DE S. (Ed.) Soja: tecnologia da produção II. Piracicaba: ESALQ/LPV, 2000. 450p.

CHAVES, M.M. et al. How plants cope with water stress in the field. Photosynthesis and growth. Annals of Botany, Oxford, v.89, p.907-916, 2002. Disponível em: <http://aob.oxfordjournals.org/ cgi/content/full/89/7/907>. Acesso em: 17 abr. 2009.

DOORENBOS J.; KASSAN A.H. Yield response to water. Rome: FAO, 1979. 221p.

DOSS, B.D.; THULOW, D.L. Irrigation, row width and plant population in relation to growth characteristics of two soybean varieties. Agronomy Journal, Madison, v.65. p.620-623, 1974. Disponível em: <http://agron.scijournals.org/cgi/content/ abstract/66/5/620>. Acesso em: 17 abr. 2009.

EMBRAPA SOJA. Cultivares de soja 2006/2007 região sul, Londrina, 2007. 72p.

EMBRAPA SOJA. Tecnologias de produção de soja, região central do Brasil, 2004. Disponível em: http://www.cnpso.embrapa.br/ producaosoja/SojanoBrasil.htm. Acesso em: 28 jan. 2009.

FLÜGGE, U.I. et al. Functional genomics of phosphate antiport systems of plastids. Physiologia Plantarum, Hoboken, v.118. p.475-482, 2003. Disponível em: <http:// www 3.interscience.wiley.com/journal/118834607/ abstract?CRETRY=1\&SRETRY=0>. Acesso em: 17 abr. 2009. doi: $10.1034 /$ j.1399-3054.2003.00137.x.

FONSECA, D.M. et al. Níveis críticos de fósforo em amostras de solo para o estabelecimento de Andropon gayanus, Brachiaria decumbens e Hyparrhenia rufa. Revista Brasileira de Ciência do Solo, Viçosa, v.12, n.4, p.49-58, 1988.

FOYER, C.H. Feedback inhibition of photosynthesis through source-sink regulation in leaves. Plant Physiology and Biochemestry, Paris, v.26, p.483-492, 1988

GOLDSCHMIDT, E.E.; HUBER, S.C. Regulation of photosynthesis by end-product accumulation in leaves of plants storing starch, sucrose, and hexose sugars. Plant Physiology, Rockville Pike, v.99, p.1443-1448, 1992.

GOPEFERT, H. et al. Eventos generalizados e seguridade Agrícola. Brasília: IPEA, Ministério do Planejamento, 1993. $281 \mathrm{p}$.

GUSS, A. et al. Exigências de fósforo para o estabelecimento de quatro espécies de Brachiaria em solos com características físioquímicas distintas. Revista Brasileira de Zootecnia, Viçosa, v.19, n.4, p.278-289, 1990.

HOFFMANN, J.A. et al. O Nitrogênio e o fósforo no crescimento da Brachiaria e do colonião em amostras de um Latossolo da região do nordeste do Paraná. Revista Brasileira Ciência do Solo, Viçosa, v.19, n.1, p.233-243, 1995.

HOLFORD, L.C.R. Soil phosphorus: its measurement and, it uptake by plants. Australian Journal of Soil Research Victoria, v.35, p.227-239, 1997. Disponível em: <http:// www.publish.csiro.au/paper/S96047.htm>. Acesso em: $17 \mathrm{abr}$. 2009. doi: $10.1071 /$ S96047.
KRON, A.P. et al. Water deficiency at different developmental stages of glycine max can improve drought tolerance. Bragantia, Campinas, v.67, p.43-49, 2008. Disponível em: $<$ http://www.scielo.br/scielo.php? pid=S 0006 $87052008000100005 \&$ script $=$ sci_abstract $>$. Acesso em: 17 abr. 2009. doi: $10.1590 / \mathrm{S} 0006-\overline{8} 7052008000100005$.

LAMBERS, H. et al. Plant physiological ecology. Berlin: Springer, 1998.

LAWLOR, D.W. Carbon and nitrogen assimilation in relation to yield: mechanisms are the key to understanding production systems. Journal of Experimental Botany, Oxford, v.53, n.370, p.773787, 2002. Disponível em: <http://jxb.oxfordjournals.org/cgi/ content/full/53/370/773>. Acesso em: 22br. 2009.

LAWLOR D.W.; CORNIC G. Photosynthetic carbon assimilation and associated metabolism in relation to water deficits in higher plants. Plant, Cell and Environment, Hoboken, v.25, p.275-294, 2002. Disponível em: <http:// www3.interscience.wiley.com/journal/118948781/abstract $>$. Acesso em: 17 abr. 2009. doi: 10.1046/j.00168025.2001.00814.x.

MEDEIROS J.F. et al. Comparação entre a evaporação em tanque classe A padrão e em um minitanque, instalados em estufa e estação meteorológica. In: ANAIS DO CONGRESSO BRASILEIRO DE AGROMETEOROLOGIA, 10., 1997 , Piracicaba, SP. Anais... Piracicaba: Sociedade Brasileira de Agrometeorologia, 1997. p.228-230.

NAFZIGER, E.D.; KOLLER, H.R. Influence of leaf starch concentration on $\mathrm{CO}_{2}$ assimilation in soybean. Plant Physiology, Rockville, v.57, p.560-563, 1976.

NAKANO, H. et al. Relationship between the suppression of photosynthesis and starch accumulation in the pod-removed bean. Australin Journal of Plant Physiology, Victoria, v.27, p.167-173, 2000.

NOVAIS, R.F.; SMYTH, T.T. Fósforo em solo e planta em condições tropicais. Viçosa: Universidade Federal de Viçosa, 1999. 399p.

PAUL, M.J.; PELLNY, T.K. Carbon metabolite feedback regulation of leaf photosynthesis and development. Journal of Experimental Botany, Oxford, v.54, p.539-547, 2003.

SANTOS, M.G. et al. Gas exchange and yeild response to foliar phosphorrus supplying in Phaselus vuagari under drought. Brazilian Journal of Plant Physiology, Campinas, v.16, p.171-179, 2004

SANTOS M.G. et al. The role of inorganic phosphate on photosynthesis recovery of commom bean after a mild water déficit Plant Science, v. 170, p. 659-664. Disponível em: <http:// www.sciencedirect.com/science?_ob=ArticleURL\&_udi=B6TBH4 HMGKG9-2\& user $=10 \&$ rdoc $=1 \& \mathrm{fmt}=\&$ orig $=$ search $\&$

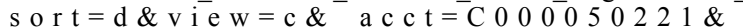
version $=1 \&$ u r 1 Vers i o $n=0 \&$ u s e ri d $=\overline{1}$ $0 \& \mathrm{md} 5=6 \mathrm{ae} 85 \mathrm{cf} 3 \mathrm{eab} 169 \mathrm{dc} 1 \mathrm{~d} 2 \mathrm{e} 519933 \mathrm{e} 00 \mathrm{ba} 9>$. doi: 10.1016 j.plantsci.2005.10.020.

SHARKEY, T.D.; SEEMANN, J.R. Mild water stress effects on carbon-reduction-cycle intermediates, ribulose bisphosphate carboxylase activity, and spatial homogeneity of photosynthesis $\mathrm{m}$ intact leaves. Plant Physiology, Rockville Pike , v.89, p.1060-1065, 1989

TEZARA, W. et al. Water stress inhibits plant photosynthesis by decreasing coupling factors and ATP. Nature, London, v.401, p.914-917, 1999. Disponível em: <http:// www.nature.com/nature/journal/v $401 / \mathrm{n} 6756 / \mathrm{full} /$ 401914a0.html>. doi: $10.1038 / 44842$. 